\title{
Heart rate variability and DNA methylation levels are altered after short-term metal fume exposure among occupational welders: a repeated-measures panel study
}

\author{
Tianteng Fan ${ }^{1}$, Shona C Fang ${ }^{1,2}$, Jennifer M Cavallari ${ }^{1,3}$, Ian J Barnett ${ }^{4}$, Zhaoxi Wang ${ }^{1}$, Li Su ${ }^{1}$, Hyang-Min Byun ${ }^{1}$, \\ Xihong Lin ${ }^{2}$, Andrea A Baccarelli, ${ }^{1,5}$ and David C Christiani ${ }^{1,5,6^{*}}$
}

\begin{abstract}
Background: In occupational settings, boilermakers are exposed to high levels of metallic fine particulate matter $\left(\mathrm{PM}_{2.5}\right)$ generated during the welding process. The effect of welding $\mathrm{PM}_{2.5}$ on heart rate variability (HRV) has been described, but the relationship between PM 2.5 . DNA methylation, and HRV is not known.

Methods: In this repeated-measures panel study, we recorded resting HRV and measured DNA methylation levels in transposable elements Alu and long interspersed nuclear element-1 (LINE-1) in peripheral blood leukocytes under ambient conditions (pre-shift) and right after a welding task (post-shift) among 66 welders. We also monitored personal $\mathrm{PM}_{2.5}$ level in the ambient environment and during the welding procedure.

Results: The concentration of welding $\mathrm{PM}_{2.5}$ was significantly higher than background levels in the union hall $\left(0.43 \mathrm{mg} / \mathrm{m}^{3}\right.$ vs. $\left.0.11 \mathrm{mg} / \mathrm{m}^{3}, \mathrm{p}<0.0001\right)$. The natural log of transformed power in the high frequency range (In HF) had a significantly negative association with $\mathrm{PM}_{2.5}$ exposure $(\beta=-0.76, p=0.035)$. pNN10 and pNN20 also had a negative association with $\mathrm{PM}_{2.5}$ exposure $\left(\beta=-0.16 \%, p=0.006\right.$ and $\beta=-0.13 \%, p=0.030$, respectively). $P M_{2.5}$ was positively associated with LINE-1 methylation $[\beta=0.79 \%, 5$-methylcytosince (\%mC), $p=0.013]$; adjusted for covariates. LINE-1 methylation did not show an independent association with HRV.
\end{abstract}

Conclusions: Acute decline of HRV was observed following exposure to welding $\mathrm{PM}_{2.5}$ and evidence for an epigenetic response of transposable elements to short-term exposure to high-level metal-rich particulates was reported.

\section{Background}

Numerous air pollution studies have shown that both acute and cumulative exposures to fine particulate matter $\left(\mathrm{PM}_{2.5}\right)$ are associated with increased risk of adverse cardiovascular events, such as the onset of atrial fibrillation (AF), incidence and recurrences of myocardial infarction, heart failure and stroke, and mortality from cardiovascular disease [1-4]. Heart rate variability (HRV) has been used as an early disease marker of adverse cardiovascular outcomes and as an indicator of cardiac

\footnotetext{
* Correspondence: dchris@hsph.harvard.edu

'Department of Environmental Health, Harvard School of Public Health, Boston, MA 02115, USA

${ }^{5}$ Department of Epidemiology, Harvard School of Public Health, Boston, MA USA

Full list of author information is available at the end of the article
}

autonomic function. It is believed that reductions in HRV alter the heart's ability to properly respond to external signals, leading to myocardial infarction [5].

In occupational settings, welders are exposed to high levels of $\mathrm{PM}_{2.5}$ generated during the welding process. The metal components of $\mathrm{PM}_{2.5}$ play an important role in its toxicity [6]; metal-rich particle exposure related to welding has been associated with increased systemic inflammation, inflammation-related endothelial dysfunction, and elevated oxidative stress $[7,8]$. For example, $\mathrm{C}$-reactive protein (CRP), an inflammatory risk factor of endothelial dysfunction, is associated with fatal and non-fatal coronary artery disease (CAD) events in a healthy population $[9,10]$. Studies have shown an association between increased circulating levels of CRP and decreased HRV in middle-aged 
men free of CAD, which suggests a relationship between ANS dysfunction induced and systemic inflammation [11]. Previous studies from the same cohort have reported an association between HRV and welding $\mathrm{PM}_{2.5}$ levels [12] and the concentration of various metal components of welding fumes [13].

Not only is inflammation associated with $\mathrm{PM}_{2.5}$, epigenetic changes have been implicated in PM-related conditions [14]. Epigenetic patterns are known to be sensitive to environmental exposures throughout the lifespan [15]. In a previous study, acute and chronic exposure to welding $\mathrm{PM}_{2.5}$ was associated with altered gene methylation [16]. DNA methylation in transposable elements, such as Alu and long interspersed nuclear elements-1 (LINE-1), which has been shown to be altered by $\mathrm{PM}_{2.5}$ exposure $[17,18]$.

Alu and LINE-1 elements are widely represented across the human genome and DNA methylation in which maintains transcriptional inactivation and integrity of the genome [19]. Studies show that decreased methylation in LINE-1 elements is associated with ischemic heart disease and stroke, as well as cardiovascular disease risk factors, such as high levels of low-density lipoprotein (LDL) and low levels of high-density lipoprotein (HDL) [20-23]. Decreased methylation has also been shown to be associated with increased vascular cell adhesion molecule-1 (VCAM-1), a biomarker of vascular inflammation [20-23], which suggests a potential functionality of DNA methylation in cardiovascular disease. A study has further reported that genetic variations in the methionine cycle affect heart rate variability which suggests the role of methylation in cardiac autonomic dysfunction and lower intake of nutritional methyl supplement is associated with the negative effect of $\mathrm{PM}_{2.5}$ on HRV [24]. However, whether DNA methylation levels in systemic circulation mediate the PM-induced cardiovascular effect measured in $\mathrm{HRV}$ is not known.

To investigate the cardiac and epigenetic changes in response to metallic welding fume exposure, we investigated the short-term effect of welding $\mathrm{PM}_{2.5}$ on resting HRV and blood DNA methylation in Alu and LINE-1 elements in a cohort of 66 male occupational welders. In addition, we tested the association between $\mathrm{PM}_{2.5}$-induced DNA methylation changes and HRV to characterize the mediation effect of DNA methylation on the relationship between welding $\mathrm{PM}_{2.5}$ and heart rate variability.

\section{Methods}

\section{Study subjects}

We recruited 66 male boilermakers free of cardiovascular disease at the Boilermaker Union Local 29, located in Quincy, Massachusetts, in a repeated-measures panel study. Written informed consent to participate in the study was obtained from each subject. The study protocol was approved by the Institutional Review Board (IRB) of the Harvard School of Public Health and the summary of population characteristics was shown in Table 1. In the union hall, there is a large, temperature-controlled classroom used by workers for break and it is outfitted with ten workstations in a separate area where the welders perform welding, cutting, and grinding tasks. Boilermakers primarily perform shielded metal arc and gas metal arc welding using base metals of mild steel (manganese alloys) and stainless steel (manganese, chromium, and nickel alloys) with electrodes composed mainly of iron with $1-5 \%$ proportions of manganese.

\section{Study design}

Six sampling cycles were performed from January 2010 to June 2012. Participants were recruited on multiple sampling cycles to perform welding. However, it was not a balanced design study and subjects had randomly missing sampling cycles. At each sampling cycle, personal air particulate exposure was monitored under work environment with and without welding activities to compare the effect of particle exposure generated during an average of five hours of welding to the background environment in the classroom with no direct welding fume exposure. Blood samples and resting HRV recordings were obtained before and after welding. A work log was used to collect personal information on work shift length, workstation, and exposure to secondhand smoke. A modified American Thoracic Society respiratory and cardiac questionnaire was used to collect medical history and medication use, demographics, and lifestyle information including smoking status and occupational history $[25,26]$.

\section{Particle exposure assessment}

Real-time personal particle exposure was continuously monitored using the light-scattering technology of a DustTrak $^{\mathrm{Tm}}$ Aerosol Monitor (TSI, Inc., St. Paul, MN)

\section{Table 1 Summary of population characteristics}

\begin{tabular}{lll}
\hline Characteristics $(\mathbf{n}=\mathbf{6 6})$ & Mean (SD) \\
\hline Age (years) & & $41(12.2)$ \\
Range & & $21-71$ \\
BMI $\left(\mathrm{kg} / \mathrm{m}^{2}\right)^{\mathrm{a}}$ & & $28.4(5.0)$ \\
Range & $\mathrm{N}$ & $16.9-38.7$ \\
Race & 55 & $\%$ \\
White & 6 & 83 \\
Black & 3 & 9 \\
Hispanic & 2 & 5 \\
Asian & 66 & 3 \\
Male & 28 & 100 \\
Current smoker ${ }^{a}$ & 43.1 \\
\hline
\end{tabular}

$\mathrm{a}=65$ due to missing questionnaire information. 
fitted with an inlet impactor designed to separate particles with a median aerodynamic diameter of less than $2.5 \mu \mathrm{m}\left(\mathrm{PM}_{2.5}\right)$. Each monitor received daily flow and calibration checks as well as yearly calibration performed by the manufacturer. Gravimetric analysis was not applied because a previous study of the same occupational cohort indicated good agreement between DustTrak ${ }^{\mathrm{Tx}}$ and gravimetric measurements [27,28]. Each monitor was placed in a padded pouch with the inlet tubing secured to the participant's shoulder around the nasal breathing area. The DustTrak ${ }^{\mathrm{Tw}}$ records $\mathrm{PM}_{2.5}$ concentration readings every ten seconds and calculates 1 -min averages throughout the course of the welding shift. The DustTrak $^{\mathrm{mm}}$ was worn during the welding shift to quantify $\mathrm{PM}_{2.5}$ exposure generated by welding, as well as over a similar period of time during the previous day, while the personal background environmental exposure was monitored in the absence of welding.

\section{Heart rate variability measurement}

Continuous heart activity was recorded using a standard three-channel, seven-lead electrode Holter monitor $\left(\mathrm{GE}^{\mathrm{mx}}\right.$ SEER Light Compact Digital Holter Recorder). Research staff helped participants to prepare for monitoring by shaving hair from each electrode site on the chest if necessary, and cleaning each electrode site with alcohol to improve conductivity. Heart rate variability was analyzed in the time and frequency domains. Time domain analysis calculated several measures of normal-to-normal (NN) intervals, including the standard deviation of the $\mathrm{NN}$ intervals (SDNN), square root of the mean squared difference of successive $\mathrm{NN}$ intervals (rMSSD), and the proportion of the number of interval differences of successive $\mathrm{NN}$ intervals greater than 10 and 20 milliseconds over the total number of $\mathrm{NN}$ intervals (pNN10 and pNN20). Frequency domain analysis evaluated how the power (variance) was distributed as a function of frequency and its fluctuation. Resting HRV was analyzed for power spectral density in the low frequency $(0.04-0.15 \mathrm{~Hz}, \mathrm{LF})$, and power in the high frequency $(0.15-$ $0.40 \mathrm{~Hz}, \mathrm{HF}$ ) [29]. SDNN, rMSSD, pNN10, pNN20, LF, and HF was calculated over a five minute resting period during which participants were seated both before and after welding work. With the exception of pNN10 and pNN20, all other measurements were not normally distributed, and thus were natural $\log (\ln )$-transformed before data analysis.

In order to control the circadian variation of HRV, participants were encouraged to participate the baseline examination on non-welding days prior to welding days. A subgroup $(n=49)$ of the participants were monitored on non-welding days.

\section{DNA methylation analysis}

Blood samples were collected from each participant before and right after welding work. Whole blood samples were collected by venous phlebotomy in EDTA tubes and promptly centrifuged on site for $15 \mathrm{~min}$. After plasma was transferred, blood buffy coats were stored on dry ice for DNA extraction using a Gentra Autopure LS Large Sample Nucleic Acid Purification System (QIAGEN Company, Venlo, Limburg, Netherlands).

DNA methylation analyses of Alu and LINE-1 elements were performed on bisulfite-treated DNA by quantitative PCR pyrosequencing using the EZ DNA Methylation Gold Kit (Zymo Research, Orange, CA, USA) as previously described in detail [30] (See Additional file 1: Table S1). For all assays, we used built-in controls to verify bisulfite conversion efficiency. We tested the proportion of 5 methylcytosine $(5 \mathrm{mC})$ at each of five $\mathrm{CpG}$ dinucleotide positions of Alu and four CpG positions of LINE-1 and calculated the overall mean level of methylation for both Alu and LINE-1 elements.

\section{Statistical analysis}

To account for correlated outcomes among boilermakers who participated in multiple sampling cycles, we used linear mixed-effects regression models with random intercepts to investigate 1) the effect of $\mathrm{PM}_{2.5}$ on $\mathrm{HRV}, 2$ ) the effect of $\mathrm{PM}_{2.5}$ on DNA methylation and 3) whether DNA methylation served as a mediator of the $\mathrm{PM}_{2.5}$ effect on HRV.

\section{Effect of $P M_{2.5}$ on HRV}

For each participant, we measured pre- and post-resting HRV outcomes over five minutes for each sampling cycle. Recordings were analyzed in both the time and frequency domains, and SDNN, rMSSD, pNN10, pNN20, LF, and HF were calculated. We used a linear mixed-effect model with random intercepts to account for correlated outcome measures repeatedly collected from the same subject. We estimated the acute effect of $\mathrm{PM}_{2.5}$ on HRV outcomes using the following model:

$$
\begin{aligned}
Y_{i j k}= & \beta_{0}+\beta_{1} *\left(P M_{2.5}\right)_{i j k}+\beta_{2} * X_{2 i j k}+\ldots \\
& +\beta_{p} * X_{p i j k}+b_{i}+e_{i j k}
\end{aligned}
$$

where for the fixed effects, $\beta_{0}$ is the overall intercept; $\beta_{1}$ is the regression coefficient representing the effect of $\mathrm{PM}_{2.5}$ on HRV outcomes; $\beta_{2} \ldots \beta_{\mathrm{p}}$ are the regression coefficients for the covariates included in adjusted models; $i=1,2, \ldots, 66$ represents the subject; $j=1,2, \ldots 6$ represents the $j^{\text {th }}$ sampling cycle; $k=1,2$ in the outcome variable represents pre- or post-welding samples, while the measurement of $\mathrm{PM}_{2.5}$ represents background or welding PM exposures. The random intercept for each subject is $b_{i}$ and the residual error term is $e_{i j k}$. Adjusted models included the covariates age, starting time of the day $(\mathrm{am} /$ $\mathrm{pm}$ ), season, sampling year, current smoking status (yes/no), and exposure to second-hand smoke (yes/no). Restricted 
maximum likelihood method was used for estimation. Significance of fixed effects was based on the Wald tests [31].

\section{Effect of $P M_{2.5}$ on DNA methylation}

For each participant, we measured DNA methylation in two blood samples (pre- and post-exposure) collected in each sampling cycle. For each blood sample, the average DNA methylation levels of both Alu and LINE-1 elements were calculated over five and four $\mathrm{CpG}$ dinucleotide positions, respectively. The effect of $\mathrm{PM}_{2.5}$ on DNA methylation levels measured as $\% 5 \mathrm{mC}$ was estimated using the same model (1). Adjusted models included the following covariates as fixed effects: age, starting time of day $(\mathrm{am} / \mathrm{pm})$, season, batch effect of methylation analysis, current smoking status (yes/no), and exposure to second-hand smoke (yes/no).

\section{Conditional effect of LINE-1 methylation on HRV}

The effect LINE-1 methylation levels on HRV after controlling for $\mathrm{PM}_{2.5}$ was estimated with model (2):

$$
\begin{aligned}
Y_{i j k}= & \beta_{0}+\beta_{1} *(L I N E-1)_{i j k}+\beta_{2} *\left(P M_{2.5}\right)_{i j k} \\
& +\ldots+\beta_{p} * X_{p i j k}+b_{i}+e_{i j k}
\end{aligned}
$$

where for the fixed effects, $\beta_{0}$ is the overall intercept; $\beta_{1}$ is the regression coefficient representing the effect of LINE-1 methylation on HRV outcomes after adjusted for $\mathrm{PM}_{2.5}$, the conditional effect of $\mathrm{PM}_{2.5}$ was estimated as $\beta_{2}$; and $\beta_{3} \ldots \beta_{\mathrm{p}}$ are the regression coefficients for the covariates included in adjusted models. We included the same covariates as in the analysis of the $\mathrm{PM}_{2.5}$ effect on HRV.

\section{Results}

\section{Personal exposure levels}

Average personal exposure levels of $\mathrm{PM}_{2.5}$ are shown in Table 2. The average welding shift was five hours. $\mathrm{PM}_{2.5}$ levels from the background environment were an average of $0.11 \mathrm{mg} / \mathrm{m}^{3}\left(\mathrm{SD}=0.14 \mathrm{mg} / \mathrm{m}^{3}\right)$, while $\mathrm{PM}_{2.5}$ during welding were an average of $0.43 \mathrm{mg} / \mathrm{m}^{3}$ ( $\mathrm{SD}=$ $\left.0.34 \mathrm{mg} / \mathrm{m}^{3}\right)$. These differences are statistically significant $(\mathrm{p}<0.0001)$.

\section{A subgroup population and baseline HRV variation}

A subgroup of 47 male boilermakers were monitored for the resting HRV on non-welding days prior to any welding tasks. This subgroup of male boilermakers have similar mean age, BMI and race distribution as the main welding group (Table 3). However, the current smoking rate is $61.2 \%$ whereas $43.1 \%$ of smokers in the welding group.

Average HRV measurements are shown in Table 4. The differences of HRV measurements between pre and postshift are not statistically significant $(\mathrm{p}>0.05)$. Whereas in
Table 2 Summary of $\mathrm{PM}_{2.5}$, HRV, and DNA methylation in

\begin{tabular}{|c|c|c|c|c|}
\hline & \multicolumn{2}{|l|}{ Mean (SD) } & \multirow{2}{*}{$\begin{array}{l}\text { Difference in } \\
\text { Measurement } \\
\text { Welding - } \\
\text { Background }\end{array}$} & \multirow[t]{2}{*}{ p-value ${ }^{a}$} \\
\hline & $\begin{array}{l}\text { Background } \\
\text { Environment }\end{array}$ & $\begin{array}{l}\text { Welding } \\
\text { exposure }\end{array}$ & & \\
\hline \multirow{3}{*}{$\begin{array}{l}\text { Personal } \mathrm{PM}_{2.5} \\
\left(\mathrm{mg} / \mathrm{m}^{3}\right)\end{array}$} & $0.11(0.14)$ & $0.43(0.34)$ & 0.32 & $<0.0001$ \\
\hline & & & $\begin{array}{l}\text { Difference in } \\
\text { Measurement }\end{array}$ & \\
\hline & Pre-shift & Post-shift & $\begin{array}{l}\text { Post-shift - } \\
\text { Pre-shift }\end{array}$ & $p$-value $e^{a}$ \\
\hline Alu (\%5mC) & $29.4(1.1)$ & $29.5(1.06)$ & 0.10 & 0.396 \\
\hline LINE-1 (\%5mC) & $82.5(1.7)$ & $82.7(1.7)$ & 0.22 & 0.240 \\
\hline SDNN (msec) & $48.2(24.2)$ & $37.8(18.7)$ & -8.7 & $<0.0001$ \\
\hline rMSSD (msec) & $26.5(19.1)$ & $21.1(11.9)$ & -4.45 & 0.001 \\
\hline pNN10 (\%) & $51.4(22.0)$ & $42.5(22.1)$ & -0.08 & 0.0002 \\
\hline pNN20 (\%) & $33.2(22.6)$ & $25.8(20.8)$ & -0.07 & 0.002 \\
\hline LF $\left(\mathrm{msec}^{2}\right)$ & $1019.4(1289.0)$ & $593.0(561.9)$ & -378.3 & 0.0003 \\
\hline $\mathrm{HF}\left(\mathrm{msec}^{2}\right)$ & $454.6(884.3)$ & $194.6(284.3)$ & -228.9 & 0.001 \\
\hline
\end{tabular}
boilermakers

${ }^{a}$ Accounting for within subject correlation.

Table 2, the decline of HRV measurements after welding exposure are statistically significant $(\mathrm{p}<0.05)$.

\section{Effect of $\mathrm{PM}_{2.5}$ on HRV}

In unadjusted models, $\mathrm{PM}_{2.5}$ was associated with decreased HRV measured in natural log-transformed SDNN, rMSSD, LF, HF and natural percentage pNN10 and pNN20 (Table 5). In covariate-adjusted models, $\mathrm{PM}_{2.5}$ was still associated with decreased pNN10, pNN20 and $\ln$ HF $(\beta=-0.16 \%, p=0.006 ; \beta=-0.13 \%$, $p=0.030$ and $\beta=-0.76, p=0.035$, respectively). The effect of $\mathrm{PM}_{2.5}$ on heart rate variability was interpreted as follows: with each $1 \mathrm{mg} / \mathrm{m}^{3}$ increase in $\mathrm{PM}_{2.5}$ exposure level, there was a $17 \%$ decrease in pNN10, 13\% decrease

Table 3 Summary of a subgroup population characteristics

\begin{tabular}{lll}
\hline Characteristics $(\mathbf{n}=\mathbf{4 9})$ & Mean (SD) \\
\hline Age (years) & & $42(11.6)$ \\
Range & & $22-71$ \\
BMI $\left(\mathrm{kg} / \mathrm{m}^{2}\right)$ & & $28.0(5.1)$ \\
Range & $\mathrm{N}$ & $16.9-38.7$ \\
Race & 39 & $\%$ \\
White & 6 & 80 \\
Black & 2 & 12 \\
Hispanic & 2 & 4 \\
Asian & 49 & 4 \\
Male & 30 & 100 \\
Current smoker & & 61.2 \\
\hline
\end{tabular}


Table 4 HRV measurements of a subgroup on nonwelding days $(n=49)$

\begin{tabular}{lllll}
\hline & Mean (SD) & & $\begin{array}{l}\text { Difference in } \\
\text { Measurement }\end{array}$ & p-value \\
\cline { 2 - 4 } & Pre-shift & Post-shift & $\begin{array}{l}\text { Post-shift - } \\
\text { Pre-shift }\end{array}$ \\
\hline SDNN (msec) & $45.4(23.5)$ & $45.5(23.1)$ & 1.9 & 0.32 \\
rMSSD (msec) & $26.5(18.5)$ & $26.4(189.3)$ & 0.69 & 0.65 \\
pNN10 (\%) & $51.97(22.0)$ & $50.1(22.9)$ & -0.56 & 0.75 \\
pNN20 (\%) & $34.1(23.2)$ & $32.1(23.8)$ & -0.65 & 0.7 \\
LF (msec $\left.{ }^{2}\right)$ & $850.3(976.1)$ & $853.4(888.2)$ & 60 & 0.43 \\
HF (msec $\left.{ }^{2}\right)$ & $427.6(804.5)$ & $407.4(719.2)$ & 3.23 & 0.97 \\
\hline Accountrg
\end{tabular}

${ }^{\mathrm{a}}$ Accounting for within subject correlation.

in pNN20, and 55\% decrease in power in the highfrequency range, adjusted for age, starting time of the day $(\mathrm{am} / \mathrm{pm})$, season, current smoking status (yes/no), and exposure to second-hand smoke.

\section{Effect of $\mathrm{PM}_{2.5}$ on DNA methylation}

We found that $\mathrm{PM}_{2.5}$ had a crude positive association with LINE-1 methylation levels $[\beta=0.81$ (\%5mC), $\mathrm{p}$ $=0.024]$. The association was significant after adjustment for covariates of age, starting time of the day $(\mathrm{am} / \mathrm{pm})$, season, current smoking status (yes/no), and secondhand smoke exposure $[\beta=0.79(\% 5 \mathrm{mC}), \mathrm{p}=0.013]$. The association of $\mathrm{PM}_{2.5}$ and Alu methylation levels was also positive but not statistically significant from both crude and adjusted analysis $[\beta=0.21(\% 5 \mathrm{mC}), \mathrm{p}=0.376$ and $\beta=0.06$ (\%5mC), $p=0.767$ ]. Results are shown in Table 6 .

\section{Conditional effect of LINE-1 methylation on HRV, adjusting for $\mathrm{PM}_{2.5}$}

To further test the mediation pathway of PM-induced LINE-1 methylation changes on HRV, we investigated the effect of LINE-1 methylation levels on HRV measurements controlled for $\mathrm{PM}_{2.5}$ exposure. In the crude analysis adjusting only for $\mathrm{PM}_{2.5}$, the results showed a positive association between LINE-1 and ln rMSSD, ln LF, and ln HF $(\beta=0.05, p=0.020 ; \beta=0.09, p=0.026$ and $\beta=0.10, p=0.043$, respectively). However, after adjusting for $\mathrm{PM}_{2.5}$ and covariates of age, starting time of the day, season, sampling year, current smoking status, and second-hand smoke, the association between LINE-1 methylation and HRV was not statistically significant (Table 7).

\section{Discussion}

We demonstrated a statistically significant effect of $\mathrm{PM}_{2.5}$ on a reduction in HRV measured by HF, pNN10, and $\mathrm{pNN} 20$, and in SDNN and rMSSD that showed a marginally significant effect. Our results confirm an inverse exposure-response relationship between $\mathrm{PM}_{2.5}$ exposure and HRV and further support evidence of an observed short-term HRV change following an average of five hours of welding exposure.

These findings also confirm a previous study showing a steep short-term decline in hourly SDNN index (SDNNi) in the first few hours post-exposure to welding $\mathrm{PM}_{2.5}$, followed by a plateau and a second period of decline in the 9-10 hours post-exposure [28]. The variability of results seen in studies where $\mathrm{PM}_{2.5}$ induces HRV alterations may be due to differences in sources and components of $\mathrm{PM}_{2.5}$. A study of highway patrol troopers with exposure to $\mathrm{PM}_{2.5}$ originating from traffic combustion showed a post-shift increase in SDNN and pNN50 [32]. The assessment of $\mathrm{PM}_{2.5}$ metal exposure from another study confirmed the inverse relationship between manganese $(\mathrm{Mn})$ and night-time rMSSD [33]. However, with increases in lead and vanadium $(\mathrm{Pb}$ and $\mathrm{V})$ concentration, statistically significant mean increases in day-time SDNNi were also reported from the same cohort [13].

A subset of the participants (47 out of 66 participants) were also monitored on non-welding days prior to welding days. We tested the differences between pre and post-shift HRV measurements and the results did not show significant changes between pre and post-shift HRV (Table 4.). However, the higher prevalence of current smokers in this subgroup may be a confounding factor in this non-significant differences between pre

Table 5 Effect of $\mathrm{PM}_{2.5}$ on HRV

\begin{tabular}{|c|c|c|c|c|c|c|}
\hline & \multicolumn{3}{|c|}{ Unadjusted regression } & \multicolumn{3}{|c|}{ Adjusted regression $^{\mathrm{a}}$} \\
\hline & $\bar{\beta}$ & $95 \% \mathrm{Cl}$ & p-value & $\bar{\beta}$ & $95 \% \mathrm{Cl}$ & $p$-value \\
\hline $\mathrm{SDNN}^{\mathrm{b}}$ (msec) & -0.31 & $(-0.54 \sim-0.08)$ & 0.008 & -0.20 & $(-0.46 \sim 0.07)$ & 0.138 \\
\hline rMSSD $^{\mathrm{b}}$ (msec) & -0.28 & $(-0.52 \sim-0.04)$ & 0.024 & -0.20 & $(-0.49 \sim 0.08)$ & 0.157 \\
\hline pNN10 (\%) & -0.16 & $(-0.26 \sim-0.06)$ & 0.002 & -0.16 & $(-0.28 \sim-0.05)$ & 0.006 \\
\hline pNN20 (\%) & -0.14 & $(-0.24 \sim-0.04)$ & 0.008 & -0.13 & $(-0.25 \sim-0.01)$ & 0.030 \\
\hline $\mathrm{LF}^{\mathrm{b}}\left(\mathrm{msec}^{2}\right)$ & -0.59 & $(-1.07 \sim-0.11)$ & 0.017 & -0.43 & $(-0.98 \sim 0.13)$ & 0.127 \\
\hline $\mathrm{HF}^{\mathrm{b}}\left(\mathrm{msec}^{2}\right)$ & -0.80 & $(-1.40 \sim-0.20)$ & 0.008 & -0.76 & $(-1.46 \sim-0.05)$ & 0.035 \\
\hline
\end{tabular}

${ }^{a}$ Adjusted for age, starting time of the day, season, sampling year, current smoking status, and second-hand smoke exposure.

${ }^{\mathrm{b}}$ The outcome measurements were natural log (In)-transformed. 
Table 6 Effect of $\mathrm{PM}_{2.5}$ on DNA methylation

\begin{tabular}{|c|c|c|c|c|c|c|}
\hline \multirow{2}{*}{$\begin{array}{l}\text { Transposable } \\
\text { elements }\end{array}$} & \multicolumn{3}{|c|}{ Unadjusted regression } & \multicolumn{3}{|c|}{ Adjusted regression $^{a}$} \\
\hline & $\beta$ & $95 \% \mathrm{Cl}$ & p-value & $\beta$ & $95 \% \mathrm{Cl}$ & $\mathrm{p}$-value \\
\hline Alu (\%5mC) & 0.21 & $(-0.26 \sim 0.67)$ & 0.376 & 0.06 & $(-0.34 \sim 0.46)$ & 0.767 \\
\hline LINE-1 (\%5mC) & 0.81 & $(0.11 \sim 1.51)$ & 0.024 & 0.79 & $(0.18 \sim 1.42)$ & 0.013 \\
\hline
\end{tabular}

${ }^{a}$ Adjusted for age, starting time of the day, season, batch effect, current smoking status, and second-hand smoke exposure.

and post-shift HRV on non-welding days. Due to incomplete data, we were not able to control the baseline HRV measurements for all participants in the final model. Based on the results and the assumption of missing at random, we assumed the variability of observed HRV measurements on welding days were unlikely due to circadian variation which is not confounding the observed negative effect of $\mathrm{PM}_{2.5}$ in this study.

Transition metal components of $\mathrm{PM}_{2.5}$ are inhaled and delivered into the airways and can catalyze the Fenton reaction to generate reactive oxygen species (ROS), leading to oxidative stress, although the exact mechanism remains unclear [34]. Oxidative stress can cause endothelial injury and inflammation followed by cardiac autonomic dysfunction, which can then be visualized in an altered heart rate pattern [35]. Recent studies have suggested that oxidative stress as a consequence of ROS accumulation induces epigenetic profile alterations in peripheral blood leukocytes to further interfere with DNA, leading to changes in gene expression and, eventually, adverse cardiovascular outcomes $[19,21]$. In addition, welding particles has been associated with increased systemic inflammation and study has reported that DNA methylation is associated with ROS and inflammatory exposure $[7,36]$. In this study we investigated the epigenetic effect of welding $\mathrm{PM}_{2.5}$, and found a significant association between welding $\mathrm{PM}_{2.5}$ and increased blood methylation level of LINE-1. Transposable element LINE-1 has more complete retrotransposon structures thus it has different biological functions from Alu, and studies have suggested that Alu and LINE-1 methylation responded differently to environmental factors $[17,37]$. Our results suggest that LINE-1 might be more sensitive to short-term exposure whereas Alu is more susceptible to cumulative exposure over time [7]. We tested the association between blood cell types and blood methylation levels in Alu and LINE-1 and found that the percentage of either neutrophils or lymphocytes, which are the major differentials in peripheral blood, was not significantly associated with methylation levels. Hence, although DNA methylation is cell-type specific, our analysis shows that blood cell differentials were not confounding the observed epigenetic effect of $\mathrm{PM}_{2.5}$ in this study.

It is generally understood that PM-induced oxidative DNA damage can interfere with the ability of DNA methyltransferase to interact with DNA to reduce methylation [38]. However, one study showed an increase in global methylation in sperm from mice exposed to particulate air pollution in an urban/industrial location, supporting the positive association of global hypermethylation and particulate exposures [39]. Along with our results, the positive association between LINE-1 methylation and welding $\mathrm{PM}_{2.5}$ suggests other factors that may play a role in PMinduced ROS. Another possible explanation may be the complex toxicity of welding exposure compositions. For example, a coke-oven worker study has reported a significant association between increased methylation of LINE-1 and exposure to PAHs [40], which are also generated from welding processes and whose genotoxic risk is well established [41]. In addition to organic chemicals, nickelinduced higher global methylation was also found in Chinese hamster G12 cells [42]. Unfortunately, there is a limitation in this study that concomitant pollutants including manganese, nickel and chromium from the practicing on a mix of standard and stainless steel welding are potential

Table 7 Conditional effect of LINE-1 methylation on HRV, controlled for PM 2.5

\begin{tabular}{|c|c|c|c|c|c|c|}
\hline & \multicolumn{3}{|c|}{ Unadjusted regression } & \multicolumn{3}{|c|}{ Adjusted regression $^{\mathrm{a}}$} \\
\hline & $\beta$ & $95 \% \mathrm{Cl}$ & $\mathrm{p}$-value & $\beta$ & $95 \% \mathrm{Cl}$ & p-value \\
\hline $\mathrm{SDNN}^{\mathrm{b}}$ (msec) & 0.04 & $(-0.000 \sim 0.08)$ & 0.053 & 0.02 & $(-0.04 \sim 0.07)$ & 0.514 \\
\hline $\mathrm{rMSSD}^{\mathrm{b}}$ (msec) & 0.05 & $(0.01 \sim 0.08)$ & 0.020 & 0.04 & $(-0.01 \sim 0.10)$ & 0.130 \\
\hline pNN10 (\%) & 0.01 & $(-0.002 \sim 0.03)$ & 0.085 & 0.02 & $(-0.01 \sim 0.04)$ & 0.189 \\
\hline pNN20 (\%) & 0.01 & $(-0.004 \sim 0.03)$ & 0.128 & 0.01 & $(-0.01 \sim 0.03)$ & 0.442 \\
\hline $\mathrm{LF}^{\mathrm{b}}\left(\mathrm{msec}^{2}\right)$ & 0.09 & $(0.01 \sim 0.17)$ & 0.026 & 0.05 & $(-0.06 \sim 0.16)$ & 0.336 \\
\hline $\mathrm{HF}^{\mathrm{b}}\left(\mathrm{msec}^{2}\right)$ & 0.10 & $(0.004 \sim 0.20)$ & 0.043 & 0.10 & $(-0.04 \sim 0.24)$ & 0.162 \\
\hline
\end{tabular}

${ }^{a}$ Adjusted for age, starting time of the day, season, sampling year, current smoking status, and second-hand smoke exposure.

${ }^{\mathrm{b}}$ The outcome measurements were natural $\log (\mathrm{In})$-transformed. 
confounders that we were unable to control the unmeasured pollutants or perform a compositional exposure assessment of to further extricate the observed epigenetic responses to welding fume. In addition, smoking was only controlled as a dichotomous variable because the smoking behavior information was collected through a lifestyle questionnaire so that the lack of accuracy might not provide us to evaluate the effect of smoking measured in quantity. Also, the possible influences of electromagnetic fields generated from welding activities (in the absence of welding fume exposures) on the HRV measurements has not been assessed.

Many studies have shown a link between altered repetitive element methylation and cardiovascular diseases [23], yet the underlying epigenetic regulatory pathways have not been identified. To understand the role of DNA methylation between PM exposure and reduced HRV, we performed mediation analysis [43] to investigate whether LINE-1 methylation is a mediator of the association between $\mathrm{PM}_{2.5}$ exposure and HRV outcomes. This method allowed us to decompose a total effect of exposure on an outcome into a direct effect of the exposure and an indirect effect of the exposure through a mediator's pathway [44]. Mediation analysis usually requires a significant association between the exposure and the mediator, and a significant association between the mediator and the outcome [43]. However, the data presented here show a non-significant positive association between LINE-1 methylation level and HRV after adjustment of $\mathrm{PM}_{2.5}$, therefore we did not see any significant mediation effect. The association between LINE1 methylation and HRV was tested after a few hours of welding exposure, which might not capture the best timing of a dose-response relationship but still suggests a link between decreased LINE-1 methylation and adverse cardiac outcomes. A limitation of this study is the impossibility of collecting tissue-specific heart cells from human subjects and lack of data on gene-specific methylation such as genes involved in regulating oxidative stress and inflammatory, since LINE-1 is a transposable element and lacks the specificity necessary to serve as a mediator in a biological pathway. In addition, the relatively small sample size of this study, though adequate for repeated-measures panel results, may be a limitation in estimating the mediation effect.

\section{Conclusions}

In summary, our results show the acute decline of HRV following the exposure of metal-rich welding $\mathrm{PM}_{2.5}$ and support evidence of a short-term cardiac response to welding exposure. We also show a short-term increase in DNA methylation in LINE-1 elements following welding exposure. These results support a systemic epigenetic response to short-term exposure to high-level metal-rich particulates, however no mediation effect of LINE-1 methylation was supported from the study. Further studies involving specific tissues and gene methylation are required to establish a more detailed mechanism for the observed cardiac responses.

\section{Additional file}

Additional file 1: Table S1. Primers and PCR conditions for DNA methylation analysis.

\section{Abbreviations}

$\mathrm{PM}_{2.5}$ : Fine particulate matter; HRV: Heart rate variability; LINE-1: Long interspersed nuclear element-1; SDNN: The standard deviation of the NN intervals; rMSSD: Square root of the mean squared difference of successive NN intervals; pNN10: The proportion of the number of interval differences of successive NN intervals greater than 10 milliseconds over the total number of NN intervals; pNN20: The proportion of the number of interval differences of successive NN intervals greater than 20 milliseconds over the total number of NN intervals; LF: Power spectral density in the low frequency $(0.04-0.15 \mathrm{~Hz})$; HF: Power spectral density in the high frequency (0.15-0.40 Hz); ROS: Reactive oxygen species.

\section{Competing interests}

The authors declare they have no actual or potential competing financial interests.

\section{Authors' contributions}

TF carried out the field sampling collection, conducted data analysis and drafted the manuscript. SCF, JCM, ZW and LS carried out and participated in data collection. ZW and LS participated in data collection and carried out the DNA extraction. IB participated in the data analysis. HMB carried out the DNA methylation analysis. $X L, D C C$ and $A A B$ participated in the design of the study and supervised the drafting of the manuscript. All authors read and approved the final manuscript.

\section{Acknowledgements}

This research was supported by the National Institute of Environmental Health Sciences (NIEHS) grant numbers R01ES009860 and P50ES000002. We thank the participants and the leadership of Local 29 of the International Brotherhood of Boilermakers, Iron Ship Builders, Blacksmiths, Forgers and Helpers in Quincy, MA.

\section{Author details}

${ }^{1}$ Department of Environmental Health, Harvard School of Public Health, Boston, MA 02115, USA. ${ }^{2}$ New England Research Institute, Watertown, MA, USA. ${ }^{3}$ University of Connecticut Health Center, Farmington, CT, USA. ${ }^{4}$ Department of Biostatistics, Harvard School of Public Health, Boston, MA, USA. ${ }^{5}$ Department of Epidemiology, Harvard School of Public Health, Boston, MA, USA. ${ }^{6}$ Pulmonary and Critical Care Unit, Massachusetts General Hospital/ Harvard Medical School, Boston, MA, USA.

Received: 2 May 2014 Accepted: 11 December 2014 Published: 16 December 2014

\section{References}

1. Link MS, Luttmann-Gibson H, Schwartz J, Mittleman MA, Wessler B, Gold DR, Dockery DW, Laden F: Acute exposure to air pollution triggers atrial fibrillation. J Am Coll Cardiol 2013, 62:816-825.

2. Koton S, Molshatzki N, Yuval, Myers V, Broday DM, Drory Y, Steinberg DM, Gerber Y: Cumulative exposure to particulate matter air pollution and long-term post-myocardial infarction outcomes. Prev Med 2013, 57:339-344.

3. Madrigano J, Kloog I, Goldberg R, Coull BA, Mittleman MA, Schwartz J: Long-term exposure to PM2.5 and incidence of acute myocardial infarction. Environ Health Perspect 2013, 121:192-196.

4. Hoek G, Krishnan RM, Beelen R, Peters A, Ostro B, Brunekreef B, Kaufman JD: Long-term air pollution exposure and cardio- respiratory mortality: a review. Environ Health 2013, 12:43. 
5. Watkinson WP, Campen MJ, Nolan JP, Costa DL: Cardiovascular and systemic responses to inhaled pollutants in rodents: effects of ozone and particulate matter. Environ Health Perspect 2001, 109(Suppl 4):539-546.

6. Taube F: Manganese in occupational arc welding fumes-aspects on physiochemical properties, with focus on solubility. Ann Occup Hyg 2013, 57:6-25

7. Bellavia A, Urch B, Speck M, Brook RD, Scott JA, Albetti B, Behbod B, North M, Valeri L, Bertazzi PA, Silverman F, Gold D, Baccarelli AA: DNA hypomethylation, ambient particulate matter, and increased blood pressure: findings from controlled human exposure experiments. J Am Heart Assoc 2013, 2:e000212.

8. du Plessis L, Laubscher P, Jooste J, du Plessis J, Franken A, van Aarde N, Eloff F: Flow cytometric analysis of the oxidative status in human peripheral blood mononuclear cells of workers exposed to welding fumes. $J$ Occup Environ Hyg 2010, 7:367-374

9. van Wijk DF, Boekholdt SM, Wareham NJ, Ahmadi-Abhari S, Kastelein JJ, Stroes ES, Khaw KT: C-reactive protein, fatal and nonfatal coronary artery disease, stroke, and peripheral artery disease in the prospective EPIC-Norfolk cohort study. Arterioscler Thromb Vasc Biol 2013, 33:2888-2894.

10. Jialal I, Kaur H, Devaraj S, Smith G: Human C-reactive protein induces endothelial dysfunction in biobreeding diabetic rats. Diab Vasc Dis Res 2013, 10:550-553.

11. von Kanel R, Carney RM, Zhao S, Whooley MA: Heart rate variability and biomarkers of systemic inflammation in patients with stable coronary heart disease: findings from the Heart and Soul Study. Clin Res Cardiol 2011, 100:241-247.

12. Cavallari JM, Eisen EA, Chen JC, Fang SC, Dobson CB, Schwartz J, Christiani DC Night heart rate variability and particulate exposures among boilermaker construction workers. Environ Health Perspect 2007, 115:1046-1051.

13. Magari SR, Schwartz J, Williams PL, Hauser R, Smith TJ, Christiani DC: The association of particulate air metal concentrations with heart rate variability. Environ Health Perspect 2002, 110:875-880

14. Brook RD, Rajagopalan S, Pope CA 3rd, Brook JR, Bhatnagar A, Diez-Roux AV Holguin F, Hong Y, Luepker RV, Mittleman MA, Peters A, Siscovick D, Smith SC Jr, Whitsel L, Kaufman JD: Particulate matter air pollution and cardiovascular disease: An update to the scientific statement from the American Heart Association. Circulation 2010, 121:2331-2378.

15. Gomes MV, Pelosi GG: Epigenetic vulnerability and the environmental influence on health. Exp Biol Med (Maywood) 2013, 238:859-865.

16. Kile ML, Fang S, Baccarelli AA, Tarantini L, Cavallari J, Christiani DC: A panel study of occupational exposure to fine particulate matter and changes in DNA methylation over a single workday and years worked in boilermaker welders. Environ Health 2013, 12:47.

17. Baccarelli A, Wright RO, Bollati V, Tarantini L, Litonjua AA, Suh HH, Zanobetti A, Sparrow D, Vokonas PS, Schwartz J: Rapid DNA methylation changes after exposure to traffic particles. Am J Respir Crit Care Med 2009, 179:572-578.

18. Tarantini L, Bonzini M, Apostoli $P$, Pegoraro V, Bollati V, Marinelli B, Cantone L, Rizzo G, Hou L, Schwartz J, Bertazzi PA, Baccerelli A: Effects of particulate matter on genomic DNA methylation content and iNOS promoter methylation. Environ Health Perspect 2009, 117:217-222.

19. Baccarelli A, Rienstra M, Benjamin EJ: Cardiovascular epigenetics: basic concepts and results from animal and human studies. Circ CardiovasC Genet 2010, 3:567-573

20. Cash HL, McGarvey ST, Houseman EA, Marsit CJ, Hawley NL, LambertMesserlian GM, Viali S, Tuitele J, Kelsey KT: Cardiovascular disease risk factors and DNA methylation at the LINE-1 repeat region in peripheral blood from Samoan Islanders. Epigenetics 2011, 6:1257-1264.

21. Cencioni C, Spallotta F, Martelli F, Valente S, Mai A, Zeiher AM, Gaetano C: Oxidative stress and epigenetic regulation in ageing and age-related diseases. Int J Mol Sci 2013, 14:17643-17663.

22. Baccarelli A, Tarantini L, Wright RO, Bollati V, Litonjua AA, Zanobetti A, Sparrow D, Vokonas P, Schwartz J: Repetitive element DNA methylation and circulating endothelial and inflammation markers in the VA normative aging study. Epigenetics 2010, 5:7.

23. Baccarelli A, Wright R, Bollati V, Litonjua A, Zanobetti A, Tarantini L, Sparrow $D$, Vokonas $P$, Schwartz J: Ischemic heart disease and stroke in relation to blood DNA methylation. Epidemiology 2010, 21:819-828.

24. Baccarelli A, Cassano PA, Litonjua A, Park SK, Suh H, Sparrow D, Vokonas P, Schwartz J: Cardiac autonomic dysfunction: effects from particulate air pollution and protection by dietary methyl nutrients and metabolic polymorphisms. Circulation 2008, 117:1802-1809.
25. Ferris BG: Epidemiology Standardization Project (American Thoracic Society). Am Rev Respir Dis 1978, 118:1-120.

26. Fang SC, Cavallari JM, Eisen EA, Chen JC, Mittleman MA, Christiani DC: Vascular function, inflammation, and variations in cardiac autonomic responses to particulate matter among welders. Am J Epidemio/ 2009, 169:848-856.

27. Kim JY, Magari SR, Herrick RF, Smith TJ, Christiani DC: Comparison of fine particle measurements from a direct-reading instrument and a gravimetric sampling method. J Occup Environ Hyg 2004, 1:707-715.

28. Cavallari JM, Fang SC, Eisen EA, Schwartz J, Hauser R, Herrick RF, Christiani DC: Time course of heart rate variability decline following particulate matter exposures in an occupational cohort. Inhal Toxicol 2008, 20:415-422.

29. Malik M: Heart rate variability. Ann Noninvasive Electrocardio/ 1996, 1:151-181.

30. Bollati V, Baccarelli A, Hou L, Bonzini M, Fustinoni S, Cavallo D, Byun HM Jiang J, Marinelli B, Pesatori AC, Bertazzi PA, Yang AS: Changes in DNA methylation patterns in subjects exposed to low-dose benzene. Cancer Res 2007, 67:876-880.

31. Bolker BM, Brooks ME, Clark CJ, Geange SW, Poulsen JR, Stevens MHH, White J-SS: Generalized linear mixed models: a practical guide for ecology and evolution. Trends Ecol Evol 2009, 24:127-135.

32. Riediker M, Devlin RB, Griggs TR, Herbst MC, Bromberg PA, Williams RW, Cascio WE: Cardiovascular effects in patrol officers are associated with fine particulate matter from brake wear and engine emissions. Part Fibre Toxicol 2004, 1:2

33. Cavallari JM, Eisen EA, Fang SC, Schwartz J, Hauser R, Herrick RF, Christiani DC: PM2.5 metal exposures and nocturnal heart rate variability: a panel study of boilermaker construction workers. Environ Health 2008, 7:36

34. Deng X, Zhang F, Rui W, Long F, Wang L, Feng Z, Chen D, Ding W: PM2.5-induced oxidative stress triggers autophagy in human lung epithelial A549 cells. Toxicol In Vitro 2013, 27:1762-1770.

35. Lodovici M, Bigagli E: Oxidative stress and air pollution exposure. J Toxicol 2011, 2011:487074

36. Tarantini $L$, Bonzini M, Tripodi A, Angelici L, Nordio F, Cantone L, Apostoli P, Bertazzi PA, Baccarelli AA: Blood hypomethylation of inflammatory genes mediates the effects of metal-rich airborne pollutants on blood coagulation. Occup Environ Med 2013, 70:418-425

37. Bollati V, Schwartz J, Wright R, Litonjua A, Tarantini L, Suh H, Sparrow D, Vokonas P, Baccarelli A: Decline in genomic DNA methylation through aging in a cohort of elderly subjects. Mech Ageing Dev 2009, 130:234-239.

38. Baccarelli A, Bollati V: Epigenetics and environmental chemicals. Curr Opin Pediatr 2009, 21:243-251

39. Yauk C, Polyzos A, Rowan-Carroll A, Somers CM, Godschalk RW, Van Schooten FJ, Berndt ML, Pogribny IP, Koturbash I, Williams A, Douglas GR, Kovalchuk O: Germ-line mutations, DNA damage, and global hypermethylation in mice exposed to particulate air pollution in an urban/industrial location. Proc Natl Acad Sci U S A 2008, 105:605-610.

40. Pavanello S, Bollati V, Pesatori AC, Kapka L, Bolognesi C, Bertazzi PA, Baccarelli A: Global and gene-specific promoter methylation changes are related to anti-B[a]PDE-DNA adduct levels and influence micronuclei levels in polycyclic aromatic hydrocarbon-exposed individuals. Int J Cancer 2009, 125:1692-1697.

41. Borska L, Fiala Z, Smejkalova J, Tejral J: Health risk of occupational exposure in welding processes I. Genotoxic risk. Acta Med (Hradec Kralove) 2003, 46:25-29.

42. Lee Y, Klein C, Kargacin B, Salnikow K, Kitahara J, Dowjat K, Zhitkovich A, Christie N, Costa M: Carcinogenic nickel silences gene expression by chromatin condensation and DNA methylation: a new model for epigenetic carcinogens. Mol Cell Biol 1995, 15:2547-2557.

43. Bauer DJ, Preacher KJ, Gil KM: Conceptualizing and testing random indirect effects and moderated mediation in multilevel models: new procedures and recommendations. Psychol Methods 2006, 11:142.

44. Baron RM, Kenny DA: The moderator-mediator variable distinction in social psychological research: Conceptual, strategic, and statistical considerations. J Pers Soc Psychol 1986, 51:1173.

doi:10.1186/1471-2458-14-1279

Cite this article as: Fan et al:. Heart rate variability and DNA methylation levels are altered after short-term metal fume exposure among occupational welders: a repeated-measures panel study. BMC Public Health 2014 14:1279. 